\title{
Studying big data using virtual escape rooms
}

\author{
Solomovich Lior ${ }^{1,2}$ \\ 1 "Kaye College", 2"Sapir College", Education in the Age of Information \\ Technology Department, Israel \\ solomovi@gmail.com
}

\begin{abstract}
The Corona period created great challenges in the teaching and learning process. This presentation describes a research based on studying the subject of big data using virtual escape rooms. Due to the period it was decided that the final task in the Big Data course would be to build a virtual escape room that deals with a topic from the world of Big Data. The aim of the study was to examine how the understanding of various topics related to Big Data is sharpened when they are taught through virtual escape rooms. Each group of students chose a topic from the world of big data and built a virtual escape room around it. Peer learning was then performed, and each group edited rooms of other groups, so that each group learned about a variety of topics related to the big data world. By monitoring peer learning it was possible to assess the nature of the learning process experienced by the group. This unique learning allows for flexibility in terms of time and place in holding meetings. The interactions between the various group members contribute to enrichment the knowledge and the development of creative ideas.
\end{abstract}

According to the results of the study, this type of learning sharpened different skills among the participants - social, communicative and thinking. It also developed a deep understanding when the escape room practically demonstrates the topic of big data in an optimal way through a variety of representations. During the activity in the escape room there is created an interesting and original connection between the materials and the ideas, open to a variety of interpretations. Digital tools are used effectively and creatively that contribute to understanding the message (Kemp, 2018).

Keywords: big data, virtual escape room, $21^{\text {st }}$ century skills

\section{Introduction.}

As part of the Big Data course taught by students in the technology marketing at Sapir College in Israel, the students developed virtual escape rooms. First the students were divided into groups of four and then they chose the topic they wanted to explore, defined the puzzles for the escape room and designed the virtual environment. Evaluation of the escape rooms was done through peer learning when each group was asked to evaluate the escape rooms of the other 
members. In this way all the students learned about other topics related to the world of big data.

The results were made through the qualitative approach. In order to understand the experience, 15 interviews were conducted with students who participated in the course. Through interviews, data were collected with the aim of finding out how the students who participated felt about the process they experienced and whether the original way in which they learned contributed to them understanding the subject of big data.

Online teaching requires to think about teaching and evaluation and plan the learning sequence, develop e-learning materials and provide a technical, pedagogical and administrative support system and design the learners' unique learning environment [2].

The game "Escape Room on the subject of Big Data" can be used as an innovative pedagogical tool that allows a deep understanding of the subject of Big Data. First, I gave some theoretical background on big data and then I focused on helping students using virtual escape rooms to study the subject. The themes of the escape rooms are very diverse, and the challenge levels are varied. and the activity includes a frame story that the participants become acquainted with the subject before entering the room.

The idea of learning through play is not new, but it gets better over the years and even expands into higher education. Incorporating play into learning contributes to the motivation, enjoyment and interest of learners as well as of teachers. games help to develop communication skills and social rules like patience and perseverance. When people play physical or online games, they get involved, get excited, take responsibility and initiative, solve problems, risk asking questions and mistakes and get instant feedback and a chance to correct.

There are very few research literatures on escape room as a teaching pedagogy. From studies conducted so far among medical students [3] and students of physics [9], escape rooms were found to be an effective teaching pedagogy both in the academic aspect and in the motivational aspect. In addition, university faculty members in the UK who have been exposed to this pedagogy have reported that escape room activity is innovative, evokes interest and enjoyment and has educational value. They estimated that they applied this pedagogy in their teaching [4].

\section{Escape room}

\subsection{What is escape room?}

Escape Room is a game where a group of participants is locked in a room and has to find their way out by solving puzzles and clues scattered around the room. Escape rooms, as a challenging leisure activity, were inspired by computer games, and in less than a decade, have become popular in many countries [6]. The game is characterized by a frame story that has a dimension 
of mystery, a defined goal and there are time / space constraints for each encounter. There is need for teamwork to succeed in getting out. A wide range of challenges of various kinds, hints that allowed to advance the game when needed [7]

\subsection{Why to teach with escape room}

Escape rooms are an expression of innovative, active, collaborative and constructivist teaching approaches that can shape learning in the best way, much more than conventional teaching. They help learners understand the value of observing problems from different perspectives, exposing them to collaborative teamwork, promoting engagement and perseverance in the task, strengthening social ties, encouraging teamwork and deepening learning through group discussion. The students' need to work together for succeeding in a task under the pressure of time allows them to develop communication skills. Moreover, escape rooms allow for the integration of technology in the classroom, as they make it possible to easily integrate websites, videos or other interactive digital material within the various puzzles of escape activities. However, the process of creating puzzles that focus on learning objectives and obligate students to engage with content from the curriculum instead of just looking for clues requires time and thought. Therefore, it is important to create quality games for the long term. Thus, after the development of the game, it will be possible to use it again and again in subsequent years. Before any application of an escape room study it is important to perform a test in order to assess the time required to complete the game and identify any error that may prevent the success of the participants $[12 ; 6]$

\subsection{Virtual escape room}

In virtual escape rooms we can play on computers or as apps on mobile devices. In the digital escape room, there may be various changes and adjustments that contain various elements taken from the physical escape room such as locks, magnets, cryptography and keys. In order to enhance the experience, there is used augmented reality to. The games in the virtual escape room can be available to a single player or to a team [10].

When developing a learning-oriented virtual escape room there are four issues to consider:

- Learning objectives: These objectives aim to process the topic and evaluate the student's learning experience and achievements and find out accordingly which indicators of change that must be made in order to improve.

- Single or multidisciplinary theme: single domain or multiple disciplines presented as part of the game experience.

- Soft Skills: Interactive action games that can help develop soft skills such as communication and teamwork.

- Troubleshooting: Developing troubleshooting challenges to make the game experience interesting for players. 


\subsection{How can the learning experience with virtual escape room can contribute to the 21st century skills?}

Traditional learning supplies very few opportunities for the development of $21^{\text {st }}$ century skills that include, among others, Communication, Collaboration, Critical Thinking and Creativity [1]. Learning in the "escape rooms" method makes it possible to cultivate each of these four skills through the activity.

An escape room implements the innovative teaching style characterized by a lecturer serving as an active learner's guide as opposed to a teacher who imparts knowledge to the passive learner; thus the lecturer role changes and he also become fertile cushion for game-based learning and 21st century learning skills.

\subsection{Why to study "big data" with escape room}

The term "big data" consists of a wide range of topics around them students created the virtual escape room. Topics such as military and police intelligence, biology (Outbreaks of pandemic), commerce, cyber warfare, digital marketing, indexing and textual information search, gambling, sports, industry. Students have made escape room about all this topic. The connection between a virtual escape room and the study of various topics related to the world of big data has allowed students a large space of exploration and creativity.

\subsection{Representative example of Virtual escape room}

Here is an example from the various rooms and topics the students made. The main theme of the group the was prediction of pandemic outbreaks.

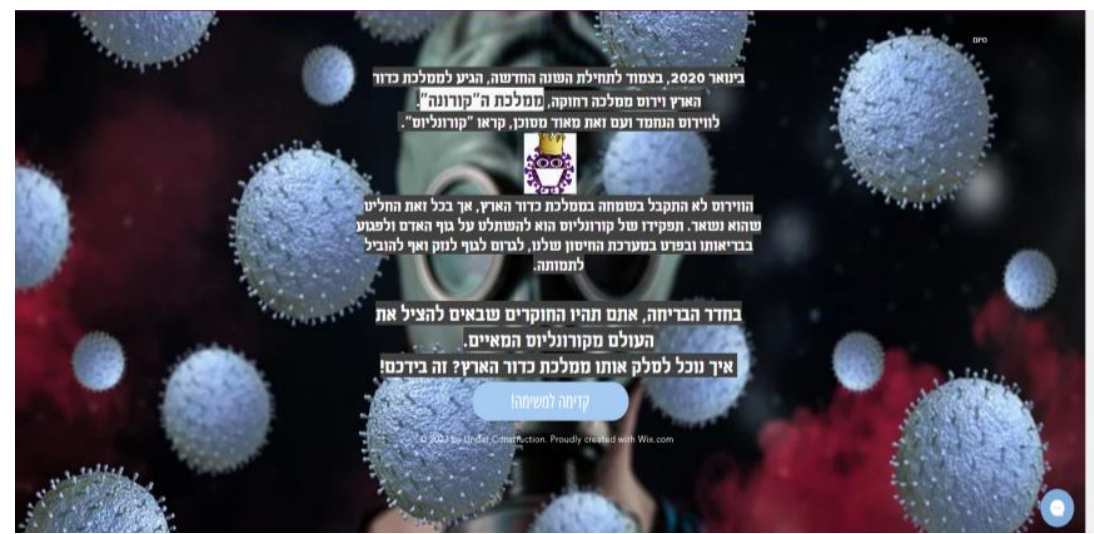

Fig. 1 - The picture was taken from the virtual escape room

The students learned about the connection between Big Data and pandemics how huge data can allow us to predict where the epidemic is about to break out. After giving tasks, reading articles, researching and delving deeper into the subject. they prepared an escape room based on graphs, tables, pictures and widgets. The participants in the escape room are not expected to do analyzes 
but rather to answer questions in the escape room aim to test understanding and insights.

In contrast to the "tasks" given in the lesson, the challenge in an escape room is to create a sequence between the clues. Each clue has two functions: one is to lead to the next riddle. The other, which is no less important, is to lead to a stage that promotes the learner to achieve the goal of the lesson.

The frame story was: you are a secret agent who sent abroad to find the vaccine against a virus that is spreading in the world. It is known that the vaccine already exists. You must go through different countries, where you will be referred by codes and clues in order to reach the vaccine.

Here are few examples for some of the riddles written by the group members. 1. You have just landed in Barcelona; you receive a message from the commander directing you to a file with 2 tickets - to Iceland and Bangladesh. And in addition, statistics on these countries. Which place will you not fly to? According to the number of tests per 1000 people and based on the graph, where is it safe not to fly?

Hint: need to check how many people live in Iceland and Bangladesh and how many tests they do through https://ourworldindata.org/grapher/populationdensity

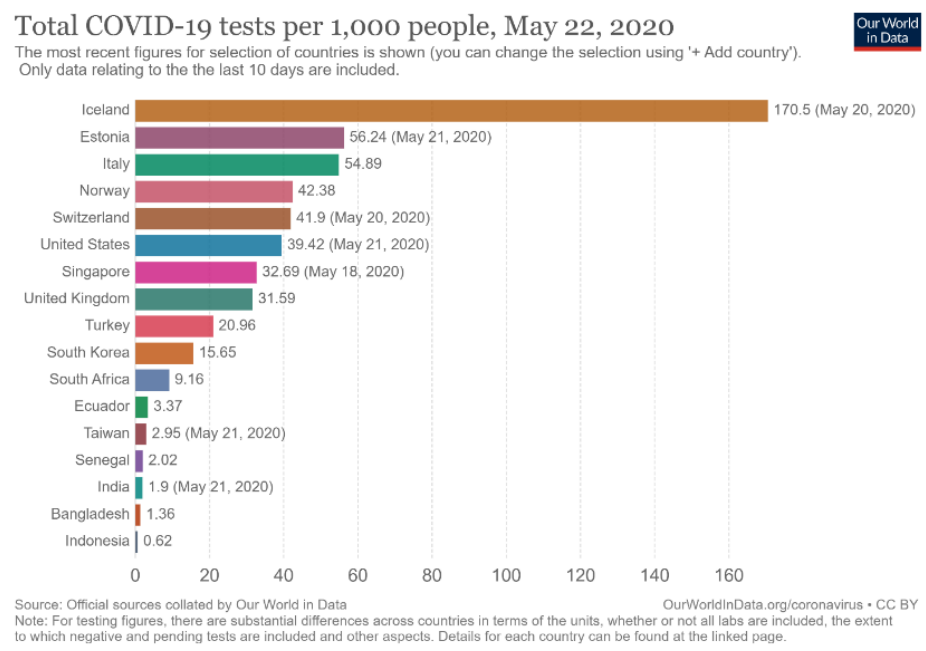

Fig. 2 - The graph was taken from the virtual escape room

2. Invented the vaccine at university with a reputation score of 71.3. https://www.statista.com/statistics/226686/world-university-rankings-byreputation/

What country are you currently flying to, to get the vaccine?

3. On the day that the number of people who recovered reaches $1,500,000$, you will be able to return to Israel. please use the website https://hgis.uw.edu/virus/

Hint: Use the cursor on the statistics site to cross-reference data 


\section{Results}

Each group of students included 4 students. All in total were 15 groups. After they finished, they participated in other students escape room and gave an anonymous feedback to their friends. To carry out the research the process was constantly reshaped thorough a brain storming with the students.

The methodological approach was Qualitative. When they finished participating in the escape room, I had Semi-structured interview containing 20 questions. After that I had 15 interviews with representatives of each group of the students which describe the experience they had.

The analysis of the data was collected from the interviews indicated on 3 themes which were very dominant sense of involvement, innovation, collaboration through the learning process.

The student's respondents during the interviews were very positive toward the process they all had. One of the responds said "The tool is very special, different, innovative and interesting. preparing the escape room was very challenging for me and I enjoyed every moment. Throughout the room preparation I learned about the subject, after that I thought about how I could get the participants who would come into my room to study The subject of autonomous cars in a creative way" another respond was "All the tasks I built for my escape room on big data could have also appeared as questions in the book but the multimedia options that exist on the net gave me the opportunity to be creative and have the learning process more interesting and fun" another responds said "In my opinion the escape room contributes greatly to the motivation of the students. It made us learn willingly, eagerly and with pleasure". One of the resonates emphasize the difficulties she overcame thanks to the group support "I did not just learn how to make the room. I worked with the trial and error method. There are still things I would like to do, working in a group helped and supported".

The application of an escape room, as part of the teaching big data, is an advanced tool adapted to learning in the 21st century and promotes important skills for this period, such as: collaboration in a teamwork, creative thinking, digital literacy, interpersonal communication and higher order thinking. Exposure to an escape room as a pedagogical tool managed to invoke a new wave of teamwork, different thinking, high motivation and great enjoyment from the preparation and implementation of the escape rooms. The sequence of leading puzzles from one to the other, the clock running on the screen and the competition between the groups motivated all the students to work hard and learn without realizing like they had done it. Looking at this activity, it seems that an escape room as a pedagogical method of teaching incorporated a central element of "Game Based Learning", a kind of learning that is characterized by the accessibility of the study material to the game. This learning has some basic components, for example fun driving motivation, 
experiential and interactive learning that is rewarded with immediate feedback and independence of the learner but also includes teamwork [12].

Despite the students' concerns, the design and performance of the escape rooms were accompanied by great creativity and enthusiasm. Their ideas had been realized and in a challenging and joint process they set up creative, highquality escape rooms that lead to learning on a wide range of topics. Along with the much planning and thought in preparing the room, all the students testified the great satisfaction and enjoyment they felt in the way of this teaching and in the great enjoyment of their students. They saw both man and women students interested, enthusiastic, learning while playing and cooperating. The variety of clues and puzzles allowed all students to experience a unique and meaningful experience and learn about different aspects of big data in a creative way. Nevertheless, this teaching method is still in its primary form. There is still a long way in front of us to test and evaluate the effectiveness of the method among students by more research.

\section{Conclusions}

In conclusion, creating a game by the students creates a sense of involvement in their learning. It enables students to discover their independence, produce sketches and test themselves, and fosters collaborations. It also invites students to learn the field of visual literacy through experience.

\section{References}

[1] Ananiadou, Katerina, and Magdalean Claro. "21st century skills and competences for new millennium learners in OECD countries." (2009).

[2] Boettcher, J. V., \& Conrad, R. M. (2016). "The online teaching survival guide: Simple and practical pedagogical tips". John Wiley \& Sons.

[3] Boysen-Osborn, Megan, Sara Paradise, and Jeffrey Suchard. "The toxiscape hunt: An escape room-scavenger hunt for toxicology education." Journal of Education and Teaching in Emergency Medicine 3.1 (2018).

[4] Clarke, S., Peel, D. J., Arnab, S., Morini, L., Keegan, H., \& Wood, O. (2017). escapED: a framework for creating educational escape rooms and Interactive Games For Higher/Further Education. International Journal of Serious Games, 4(3), 73-86.

[5] Dwyer, C. P., M. J. Hogan, and I. Stewart. "An integrated critical thinking framework for the 21st century. Thinking Skills and Creativity, 12, 43-52." (2014).

[6] Abdul Jabbar, Azita Iliya, and Patrick Felicia. "Gameplay engagement and learning in game-based learning: A systematic review." Review of educational research 85.4 (2015): 740-779.

[7] Nicholson, Scott. "Creating engaging escape rooms for the classroom." Childhood Education 94.1 (2018): 44-49.

[8] Qian, Meihua, and Karen R. Clark. "Game-based Learning and 21st century skills: A review of recent research." Computers in Human Behavior 63 (2016): 50-58.

[9] Vörös, Alpár István Vita, and Zsuzsa Sárközi. "Physics escape room as an educational tool." AIP Conference Proceedings. Vol. 1916. No. 1. AIP Publishing LLC, 2017. 
[10] Ouariachi, Tania, and Elving JL Wim. "Escape rooms as tools for climate change education: an exploration of initiatives." Environmental Education Research (2020): 114.

[10] Kemp, Henry D., et al. "Virtual Reality Escape Room." (2018).

[11] Zhang, Xiyuan, Jing-Qi Lu, and Kyoungju Park. "Interaction Design for Room Escape Virtual Reality Games." TECHART: Journal of Arts and Imaging Science 5.4 (2018): 2429.

[12] Mystakidis, Stylianos, Enrique Cachafeiro, and Ioannis Hatzilygeroudis. "Enter the Serious E-scape Room: A Cost-Effective Serious Game Model for Deep and Meaningful Elearning." 2019 10th International Conference on Information, Intelligence, Systems and Applications (IISA). IEEE, 2019. 